\title{
Fuel Effects on a Low-swirl Injector for Lean Premixed Gas Turbines
}

\author{
D. Littlejohn and R. K. Cheng \\ Environmental Energy Technologies Division \\ Lawrence Berkeley National Laboratory \\ Berkeley, CA 94720, USA
}

Corresponding Author:

David Littlejohn

Lawrence Berkeley National Laboratory

MS 70-108B, 1 Cyclotron Rd.

Berkeley, CA 94720

USA

Work: $\quad 15104867598$

Fax: $\quad 15104867303$

E-Mail: DLittlejohn@lbl.gov

COLLOQUIM 11. IC ENGINE AND GAS TURBINE COMBUSTION

SHORT TITLE: Fuel Effects on Low-swirl injector

KEYWORDS: gas turbines, lean premixed, swirl, NOx, alternate fuels

\begin{tabular}{|l|l|}
\hline Word Count: & $\mathbf{5 8 1 0}$ \\
\hline Main Text (from MS Word) & $\mathbf{3 2 5 0}$ \\
\hline Equations (2 single line single column) & 30 \\
\hline Tables & \\
\hline Table 1 (M1) & 134 \\
\hline Table 2 (M1) & 218 \\
\hline Figures (including captions) & \\
\hline Figure 1 (M1) & 144 \\
\hline Figure 2 (M1) & 216 \\
\hline Figure 3 (M1) & 241 \\
\hline Figure 4 (M1) & 136 \\
\hline Figure 5 (M1) & 200 \\
\hline Figure 6 (M1) & 220 \\
\hline Figure 7 (M1) & 237 \\
\hline Figure 8 (M1) & 279 \\
\hline Figure 9 (M1) & 157 \\
\hline References (formula) & $\mathbf{3 4 9}$ \\
\hline
\end{tabular}




\begin{abstract}
Laboratory experiments have been conducted to investigate the fuel effects on the turbulent premixed flames produced by a gas turbine low-swirl injector (LSI). The lean-blow off limits and flame emissions for seven diluted and undiluted hydrocarbon and hydrogen fuels show that the LSI is capable of supporting stable flames that emit $<5$ ppm $\mathrm{NO}_{\mathrm{x}}\left(@ 15 \% \mathrm{O}_{2}\right)$. Analysis of the velocity statistics shows that the non-reacting and reacting flowfields of the LSI exhibit similarity features. The turbulent flame speeds, $S_{\mathrm{T}}$, for the hydrocarbon fuels are consistent with those of methane/air flames and correlate linearly with turbulence intensity. The similarity feature and linear $S_{\mathrm{T}}$ correlation provide further support of an analytical model that explains why the LSI flame position does not change with flow velocity. The results also show that the LSI does not need to undergo significant alteration to operate with the hydrocarbon fuels but needs further studies for adaptation to burn diluted $\mathrm{H}_{2}$ fuels.
\end{abstract}

\title{
1. INTRODUCTION
}

Power generation turbines operating on natural gas are subjected to stringent emission rules and many urban areas have $\mathrm{NO}_{\mathrm{x}}$ requirements of $<5 \mathrm{ppm}$ (corrected to $15 \% \mathrm{O}_{2}$ ). Recent research has led to development of effective control technologies based on lean premixed combustion, such as catalytic combustors [1], trapped vortex combustors [2], and metal fiber combustors [3]. Our low-swirl injector (LSI) [4] provides another option that avoids altering engine layout or operating cycle. As more mid-size turbines are deployed in locations with readily available alternate fuels such as landfills, paper mills, and oil platforms, meeting emissions goals while using different fuels presents great challenges. This is due to differences in combustion properties and their interactions with turbulence that affect flame stability, emissions, and 
turndown performance. Our goal is to investigate the fuel effects on turbulent premixed flames in the LSI to develop an engineering method to adapt it to operate on alternate fuels. The approach is to investigate lean blow-out (LBO), emissions and the flowfield characteristics to gain the fundamental insights for optimizing the LSI for fuel-flexibility.

\section{BACKGROUND}

Lean premixed combustion is a proven dry-low- $\mathrm{NO}_{\mathrm{x}}(\mathrm{DLN})$ method for natural gas-powered turbines. Most DLN engines emit $\mathrm{NO}_{\mathrm{x}}<25 \mathrm{ppm}$ and $\mathrm{CO}<50 \mathrm{ppm}$ (both @ 15\% $\mathrm{O}_{2}$ ). But attaining ultra-low emissions of $<5 \mathrm{ppm} \mathrm{NO}_{\mathrm{x}}$ requires that turbines operate at conditions close to the lean blowoff limit (LBO) where combustors are susceptible to combustion oscillations. In a previous paper [4] we reported the development of a LSI based on a low-swirl flame stabilization method that has been developed as a laboratory configuration for studying flame/turbulence interactions [5-8]. Results at turbine conditions $\left(500<\mathrm{T}_{0}<730 \mathrm{~K}, 6<\mathrm{P}_{0}<15 \mathrm{~atm}, 12<\mathrm{U}_{0}<48\right.$ $\mathrm{m} / \mathrm{s}$ ) show that the LSI produces stable flames with $\mathrm{NO}_{\mathrm{x}}$ and $\mathrm{CO}$ below $2 \mathrm{ppm}\left(@ 15 \% \mathrm{O}_{2}\right)$ at the leanest conditions. Further work has led to a second LSI that has been evaluated in a single cylindrical combustor and in a multi-injector annular combustor at simulated engine conditions [9]. The study showed that the LSI has good performance characteristics, and is stable over a wide range of conditions where $\mathrm{NO}_{\mathrm{x}}<5 \mathrm{ppm}$ and $\mathrm{CO}$ well below the acceptable limit of 400 ppm. The flame does not have a propensity to become unstable towards blowoff or show undesirable injector-to-injector interaction. Testing of this LSI prototype in a 7 MW gas turbine is scheduled in 2006.

The heart of the LSI is a swirler evolved from atmospheric low-swirl burners [10]. The swirler section is $2.8 \mathrm{~cm}$ long $\left(\mathrm{L}_{\mathrm{s}}\right)$, and has an outer radius of $3.17 \mathrm{~cm}$ (Fig. 1) and sixteen curved vanes 
(vane angle $\alpha=42^{\circ}$ at the exit) attached to the outer surface of a $R_{c}=2 \mathrm{~cm}$ centerchannel. The open centerchannel allows a portion of reactants to remain unswirled and this nonswirling flow inhibits flow recirculation and promotes formation a divergent flowfield, a key feature of the

flame stabilization mechanism [8]. To control the mass ratio, $m=m_{c} / m_{s}$, between the flows through the centerchannel, $m_{c}$, and the swirled annulus, $m_{s}$, a perforated screen is fitted at the entrance of the centerchannel (Fig. 1 right). From Ref $[4,11]$ the swirl number definition is:

$$
S=\frac{2}{3} \tan \alpha \frac{1-R^{3}}{1-R^{2}+m^{2}\left(1 / R^{2}-1\right)^{2} R^{2}}
$$

Here the ratio of the radii of the centerchannel and injector, $\mathrm{R}$, is 0.63 and the screen blockage controls $m$ and hence $S$. The LSI for this study is slightly different than an earlier version [4] in that it uses the swirler for the second prototype. Fitted with a 58\% blockage screen, this LSI has $S=0.57$ compared to $S=0.5$ from the earlier study. Otherwise, all dimensions e.g. exit tube length of $l_{i}=9.5 \mathrm{~cm}$ and $45^{\circ}$ tapered edge, remain unchanged.

\section{EXPERIMENTAL SYSTEM AND DIAGNOSTICS}

For the lean blowout (LBO) and Particle Image Velocimetry (PIV) investigations, the LSI was mounted on a cylindrical settling chamber. Air (up to 1800 LPM) enters at the side of a $25.4 \mathrm{~cm}$ diameter chamber and flows into the LSI via a centrally placed $30 \mathrm{~cm}$ long straight tube. Air flow is adjusted by a valve and monitored by a turbine meter, and fuel (Table I) is injected in the air supply to ensure a homogeneous mixture for the injector. Both the fuel and the PIV seeder flows are controlled by mass flow controllers and set according to a predetermined value of $\phi$ with a PC. 
The fuels listed in Table I consist of hydrocarbons, $\mathrm{N}_{2}$ and $\mathrm{CO}_{2}$-diluted $\mathrm{CH}_{4}$ to simulate landfill and biomass fuels, $\mathrm{H}_{2}$-enriched $\mathrm{CH}_{4}$ to simulate refinery gas and $\mathrm{CO}_{2}$-diluted $\mathrm{H}_{2}$. Variations in the combustion properties are shown in Table I by the stoichiometric adiabatic flame temperatures, $\mathrm{T}_{\mathrm{ad}}$, and laminar flame speeds, $\mathrm{S}_{\mathrm{L}}$. For the blended fuels, these properties were calculated using an algorithm by Zhang et al. [12]. The Wobbe Index is used commercially as an indicator of fuel interchangeability and the range of values (Table I) for our fuels are equivalent to those from landfill gas to liquified petroleum gas.

Emission measurements were performed with a Horiba PG-250 analyzer, calibrated using 7.9 ppm NO in $\mathrm{N}_{2}$ and 31.8 ppm CO in $\mathrm{N}_{2}$ (Scott Specialty Gases). The instrument has an accuracy of $\pm 0.5 \mathrm{ppm}$ for $\mathrm{NO}_{\mathrm{x}}$. To measure emissions, flames were enclosed in a $16 \mathrm{~cm}$ diameter, $20 \mathrm{~cm}$ high quartz tube and sampled with a probe place a few $\mathrm{cm}$ above the center of the tube. This arrangement is similar to the atmospheric rig used previously [4]. The collected exhaust gas was cooled and water was removed with a dessicant before it flowed into the analyzer.

To facilitate PIV data collection, the non-reacting flows and the flames were not enclosed. Details of the PIV system and data analysis are described in [4]. It has a New Wave Solo PIV laser with double $120 \mathrm{~mJ}$ pulses at $532 \mathrm{~nm}$ and a Kodak/Red Lake ES 4.0 digital camera with 2048 by 2048 pixel resolution. The optics were configured to capture a field of view of $13 \mathrm{~cm}$ by $13 \mathrm{~cm}$. A cyclone particle seeder seeds the air flow with $0.3 \mu \mathrm{m} \mathrm{Al}_{2} \mathrm{O}_{3}$ particles. Data analysis was performed on the 224 image pairs recorded for each experiment using software developed by Wernet [13]. Using $64 \times 64$ pixels cross-correlation interrogation regions with $50 \%$ overlap, this rendered a spatial resolution of approximately $2 \mathrm{~mm}$. 


\section{RESULTS}

\subsection{Flame Stability and Lean Blowoff}

Flame stability and LBO were determined at volumetric flow rates $300<\mathrm{Q}<1880$ LPM, corresponding to bulk flow velocities of $3<\mathrm{U}_{0}<9 \mathrm{~m} / \mathrm{s}$. Fig. 2(a) shows LBO data for methane. The open flame data at STP [4] are shown as the baseline. The data at higher inlet temperatures and pressures ( 1 to $14 \mathrm{~atm}, 620-770 \mathrm{~K}$ ) were obtained from enclosed configurations simulating a gas turbine combustor and they show the lowest LBO occur at heated atmospheric tests in a quartz rig [4]. These data also show that the LSI can operate up to $\mathrm{U}_{0}=85 \mathrm{~m} / \mathrm{s}$, and that LBO remains relatively insensitive to $\mathrm{U}_{0}$. This is a desirable feature for turbines for it indicates that the LBO will not edge closer to the operating point of the combustor when the load increases. In Fig 2(b) $\mathrm{LBO}$ values are essentially the same for $\mathrm{CH}_{4}, \mathrm{C}_{3} \mathrm{H}_{8}, 0.5 \mathrm{CH}_{4} / 0.5 \mathrm{CO}_{2}$, and $0.6 \mathrm{CH}_{4} / 0.4 \mathrm{~N}_{2}$. The dilution of $\mathrm{CH}_{4}$ by inerts has no observable effect on LBO. LBO is slightly lower for $\mathrm{C}_{2} \mathrm{H}_{4}$ and $0.6 \mathrm{CH}_{4} / 0.4 \mathrm{H}_{2}$, which have higher flame speeds than the other fuels. The LBO values for $\mathrm{H}_{2}$ are very low and do not show a significant effect due to dilution. However, the stability ranges for $\mathrm{H}_{2}$ fuels are limited because the flames tend to reattach to the burner rim at $\phi>0.30$.

$\mathrm{NO}_{\mathrm{x}}$ and $\mathrm{CO}$ emissions from flames at $\mathrm{Q}=1500 \mathrm{LPM}\left(\mathrm{U}_{0}=7 \mathrm{~m} / \mathrm{s}\right)$ are shown in Figure 3. Only data for the hydrocarbon fuels are plotted as emissions from $\mathrm{H}_{2}$ fuels were below detectable limits. For the hydrocarbon fuels, $\mathrm{NO}_{\mathrm{x}}$ has an exponential dependence on $\phi$, and at a given $\phi$, emissions show a dependence on Wobbe Index, consistent with the higher heat content of these fuels. However, the significant implication of these data is that regardless of fuel content the LSI supports stable flames emitting $<5$ ppm NOx and the conditions are well above the LBO point.

As suggested by Figure 3, flame temperature is an important parameter in $\mathrm{NO}_{\mathrm{x}}$ formation in the LSI. The plot of $\mathrm{NO}_{\mathrm{x}}$ vs. $\mathrm{T}_{\mathrm{ad}}$ in Figure 4 shows that $\mathrm{NO}_{\mathrm{x}}$ correlates well with $\mathrm{T}_{\mathrm{ad}}$ and is 
consistent with data at high $\mathrm{T}_{0}, \mathrm{P}_{0}$ and $\mathrm{U}_{0}[4]$. As discussed previously, the LSI flow has little or no recirculation, which may explain why the $\mathrm{NO}_{\mathrm{x}}$ production depends primarily on flame temperature.

\subsection{Flowfield Analysis}

Table II shows the PIV experimental conditions consisting of three non-reacting flows and sixteen flames. For hydrocarbon flames, their stoichiometries were set at the conditions where $\mathrm{NO}_{\mathrm{x}} \approx 5 \mathrm{ppm}$ to compare them at the conditions that meet the emission goals. For the diluted hydrogen fuels, flames at $\phi=0.25$ and 0.30 were studied.

The centerline profiles for three non-reacting flows are compared in Figure 5. The similarity feature of the flowfields is shown by the normalized $U / \mathrm{U}_{0}$ profiles of Figure 5(a) collapsing onto a consistent trend. In a previous paper, [14] two parameters were introduced to characterize the nearfield region. The first is the virtual origin, $\mathrm{x}_{0}$, of the divergent flow, obtained by extrapolating the linear velocity decay region downstream of the exit (Fig 5(a)), and second is the slope of the linear extrapolation that quantifies the normalized axial divergence rate, $a_{x}=$ $d U / d x / U_{0}$. Values of $\mathrm{x}_{0}$ and $\mathrm{a}_{\mathrm{x}}$ for the three flows are given in Table II and they are very close. Profiles of the normalized 2D turbulent kinetic energy, $\mathrm{q}^{\prime}=\left(\left(\mathrm{u}^{, 2}+\mathrm{v}^{, 2}\right)^{1 / 2}\right) / 2$ of Fig $5(\mathrm{~b})$ show that within the linear velocity decay region, turbulence along the centerline remains constant. But the $2: 1$ ratio between $u^{\prime}$ and v' indicates that it is anisotropic. These characteristics can be attributed to the effect of annulus swirling flow. In the farfield, slight increases in $\mathrm{q}^{\prime} / \mathrm{U}_{0}$ at $\mathrm{x}>60$ $\mathrm{mm}$ are consistent with the formation of a very weak recirculating zone [4].

Radial profiles of the non-reacting flows at $x=15 \mathrm{~mm}$ are shown in Fig 6, where they all exhibit similarity behavior. In Fig $6(\mathrm{a})$, the $\mathrm{U} / \mathrm{U}_{0}$ profiles have a flat central region corresponding to the 
centerchannel non-swirling flow flanked by two velocity peaks, corresponding to the swirling flow. In Fig 6(b), linear distribution of the V/U $\mathrm{U}_{0}$ profiles within the center region $(-15<\mathrm{r}<15$ $\mathrm{mm}$ ) show that the normalized radial divergence rates $\mathrm{a}_{\mathrm{r}}=d V / d x / U_{0}$ are about half that of $\mathrm{a}_{\mathrm{x}}$. Therefore, the overall features of the nearfield are consistent with those of other divergent flows (e.g. stagnating flows). The q'/ $\mathrm{U}_{0}$ profiles (Fig 6(c)) have relatively flat distributions in the center regions surrounded by intense turbulence peaks. The shear stresses (not shown) at the center regions are very low $(\overline{u v} \approx 0.005 \mathrm{~m} / \mathrm{s})$ and increase to very high levels $(\overline{u v} \approx 1.5 \mathrm{~m} / \mathrm{s})$ towards the swirling regions. These velocity statistics show that the LSI produces a uniform central region with low shear stresses for flame stabilization.

Centerline profiles for reacting flows are compared in Figure 7. Only the eight flames with $9.3<$ $\mathrm{U}_{0}<9.6 \mathrm{~m} / \mathrm{s}$ are shown for clarity. Despite the large difference in the farfield, all $\mathrm{U} / \mathrm{U}_{0}$ of Fig 7 (a) have linear velocity decays near the LSI exit. The positions where profiles deviate from linear decay trends correspond to the leading edges of the turbulent flame zones. From these centerline profiles, $\mathrm{a}_{\mathrm{x}}$ and $\mathrm{x}_{0}$ for the nearfield linear decay regions can be deduced. Results listed in Table II show that the flames increase both $\mathrm{a}_{\mathrm{x}}$ and $\mathrm{x}_{0}$ to demonstrate an influence of the flame on mean characteristics of the upstream reactant flow. For hydrocarbon flames, the majority of the $a_{x}$ values are around $-0.014 \mathrm{~mm}^{-1}$ compared to $\mathrm{a}_{\mathrm{x}}=-0.085 \mathrm{~mm}^{-1}$ for the non-reacting flows. For the diluted $\mathrm{H}_{2}$ flames, the increases in $\mathrm{a}_{\mathrm{x}}$ are smaller, averaging $-0.011 \mathrm{~mm}^{-1}$ and their $\mathrm{U} / \mathrm{U}_{0}$ profiles have different shapes than the hydrocarbon flames. This seems to be associated with the lower heat release compared to the hydrocarbon flames. Though the hydrocarbon flame profiles are consistent in the nearfield, their farfield features show dependence on heat release. Significant flow accelerations are found only in the $\mathrm{C}_{2} \mathrm{H}_{4}$ and $0.5 \mathrm{CH}_{4} / 0.5 \mathrm{H}_{2}$ flames, while other hydrocarbon flame profiles have relatively flat distribution. The corresponding q'/ $\mathrm{U}_{0}$ profiles of 
Fig 7(b) show that the fluctuation levels at the LSI exit are slightly higher than in the nonreacting flows. But the anisotropic ratio $u^{\prime}: v^{\prime}$ remains unchanged. The $\mathrm{q}^{\prime} / \mathrm{U}_{0}$ levels remain relatively flat through the flame brushes and the increases in the farfield at $x>80 \mathrm{~mm}$ corresponds to flames that produce weak recirculation.

Figure 8 shows radial profiles at $\mathrm{x}=15 \mathrm{~mm}$ for flames of Fig 7 . These positions are below the flame brushes so that the results can be compared with those of Fig 6 . Although the $U / \mathrm{U}_{0}$ profiles in Fig 8(a) and Fig 6(a) have similar features, there are quantitative differences. Within the central flat regions, $\mathrm{U} / \mathrm{U}_{0}$ levels decrease to 0.5 for the two diluted $\mathrm{H}_{2}$ flames, and 0.3 for hydrocarbon flames. These changes correspond to increases in $\mathrm{a}_{\mathrm{x}}$ and $\mathrm{x}_{0}$. The center regions are also slightly wider than in the non-reacting flows. Another difference is peak velocity in the surrounding swirl annulus increasing from $\mathrm{U} / \mathrm{U}_{0}=1.2$ in non-reacting flows to 1.5 in the flames.

The $v / \mathrm{U}_{0}$ profiles of Fig $8(\mathrm{~b})$ all collapse onto a consistent distribution, giving further evidence for flow similarity in the divergent flow regions upstream of the flames. The slopes of the center region are also larger, but the 2:1 ratio between $a_{x}$ and $a_{r}$ is preserved. Another observable effect of the flame is that the minimum and maximum $\mathrm{V} / \mathrm{U}_{0}$ values corresponding to the $\mathrm{U} / \mathrm{U}_{0}$ peaks also increase to show higher radial outflow. In Fig $8(\mathrm{c})$, the q'/ $\mathrm{U}_{\mathrm{o}}$ levels in the center region are more scattered due to the influence of flames but the overall shape remain the same as in Fig 6(c).

Our flowfield analysis indicates that the overall effect of the flame is that of an aerodynamic blockage against the flow out of the LSI. The net effects are a systematic shift of the divergence flow into the LSI, increases in the divergence rates, and increases in $\mathrm{U}$ and $\mathrm{V}$ in the swirl 
regions. These effects are weaker for flames with low heat releases. Despite these systematic changes, the similarity features of the center region are preserved.

\subsection{Turbulent Flame Speed}

The turbulent flame speed, $S_{\mathrm{T}}$ is the basic turbulent flame property that explains the LSI stabilization mechanism because the freely propagating flame settles at the point within the center divergent flow region where the mean flow velocity is equal and opposite to $\mathrm{S}_{\mathrm{T}}$. Although the definition of $S_{\mathrm{T}}$, its linear or non-linear dependence on $\mathrm{u}^{\prime}$ [15] and also its theoretical significance [16] have been subject of much debate, the fact that the LSI supports stable flames from $3<\mathrm{U}_{0}<85 \mathrm{~m} / \mathrm{s}$ indicates that the $\mathrm{S}_{\mathrm{T}}$ deduced from the LSI has practical engineering significance, and provides necessary insight for further development. From previous studies using LSBs with air-jets $[17,18]$, it has been shown that $\mathrm{S}_{\mathrm{T}} / \mathrm{S}_{\mathrm{L}}$ correlates linearly with u'/S $\mathrm{S}_{\mathrm{L}}$. More recent data from the $\mathrm{CH}_{4} /$ air LSI flames at $7<\mathrm{U}_{0}<22 \mathrm{~m} / \mathrm{s}$ [14] and from two $5.08 \mathrm{~cm}$ ID LSBs of $\mathrm{R}=0.8$ and $0.6[10]$ give further support to this correlation.

The $S_{\mathrm{T}}$ deduced from the current data are listed in Table II. Here, as in [14], $S_{\mathrm{T}}$ is defined by the velocity at the point where the centerline $U_{0}$ profile deviates from its initial linear decay. The effects of fuel composition on $\mathrm{S}_{\mathrm{T}}$ are shown by their values listed in Table II. Despite the low heat release rates, the $S_{T}$ of the diluted $H_{2}$ flames are higher than the $S_{T}$ of the hydrocarbon flames. In Table II, only the $\mathrm{u}^{\prime} / \mathrm{S}_{\mathrm{T}}$ and $\mathrm{S}_{\mathrm{T}} / \mathrm{S}_{\mathrm{L}}$ for the hydrocarbon flames are listed because reliable $S_{L}$ data for very lean diluted $\mathrm{H}_{2}$ mixtures are not available. From Fig. 9 it can be seen that the $S_{\mathrm{T}}$ of the hydrocarbon flames are consistent with previous results $[14,18]$ where they are well within the experimental scatter. The inclusion of the twelve hydrocarbon flames did not affect the correlation of $\mathrm{S}_{\mathrm{T}} / \mathrm{S}_{\mathrm{L}}=1+2.16 \mathrm{u} / \mathrm{S}_{\mathrm{L}}$. Although the $\mathrm{S}_{\mathrm{T}}$ for diluted $\mathrm{H}_{2}$ cannot be 
compared directly with hydrocarbon flame data, the fact that their $\mathrm{S}_{\mathrm{T}}$ are higher strongly suggests that their turbulent flame speeds will not be consistent with those in Fig. 9.

\section{DISCUSSION}

Ref. [14] reports that the similarity features of divergent flow in the nearfield coupled with a linear correlation of $\mathrm{S}_{\mathrm{T}}$ give an explanation on why the flame remains stationary regardless of $\mathrm{U}_{0}$. This stems from a balanced equation at the leading edge of the flame brush, $\mathrm{x}_{\mathrm{f}}$,

$$
1-\frac{d U}{d x} \frac{\left(x_{f}-x_{o}\right)}{U_{o}}=\frac{S_{T}}{U_{0}}=\frac{S_{L}}{U_{0}}+\frac{2.16 u^{\prime}}{U_{o}} \quad \text { Eq. } 2
$$

On the LHS, $d U / d x / U_{o}$ is the normalized axial divergence rate $\mathrm{a}_{\mathrm{x}}$. As shown in Table II, the values for the hydrocarbon flames are about $-0.014\left(\mathrm{~mm}^{-1}\right)$. On the far RHS, contributions from $\mathrm{S}_{\mathrm{L}} / \mathrm{U}_{0}$ become small for large $\mathrm{U}_{0}$ because $\mathrm{S}_{\mathrm{L}}$ for lean flames are typically from $0.1-1.5 \mathrm{~m} / \mathrm{s}$. The second term on the RHS is dominant and is constant because $u^{\prime} / \mathrm{U}_{0}$ is controlled by the perforated plate. Consequently, $\mathrm{x}_{\mathrm{f}}-\mathrm{x}_{0}$ does not vary significantly for large $\mathrm{U}_{0}$.

Ref. [14] indicates that a practical application of Eq. 2 is to predict flashback velocity for natural gas flames. Also, with improved knowledge of $\mathrm{S}_{\mathrm{T}}$ correlation and coupling of the nearfield divergence flow structures with combustion heat release, it can be the basis for developing guidelines to adapt the LSI for different fuels. Since the hydrocarbon flames have the same effect as $\mathrm{CH}_{4}$ flames on $\mathrm{a}_{\mathrm{x}}$ and $\mathrm{x}_{0}$ and have the same $\mathrm{S}_{\mathrm{T}}$ correlation, significant adjustments may be unnecessary for the current LSI to utilize hydrocarbon fuels with higher and lower Wobbe indices. Of course, this conjecture must be verified by higher velocity tests at elevated $\mathrm{T}_{0}$ and $\mathrm{P}_{0}$. As to the highly lifted diluted hydrogen flames, experience indicates that they will eventually become unstable at higher $\mathrm{U}_{0}$. To improve stability, they need to be drawn closer to the exit. Eq. 
2 shows that a larger $a_{x}$ would be necessary and this can be accomplished by increasing $\mathrm{S}$. As flame speed correlations for the $\mathrm{H}_{2}$ fuels are likely to be different, Eq. 2 offers a means to estimate how flame positions changes with $\mathrm{a}_{\mathrm{x}}$ and different $\mathrm{S}_{\mathrm{T}}$ correlation.

\section{CONCLUSIONS}

Laboratory experiments have been performed to investigate the fuel effects on a low-swirl injector developed for natural gas turbines. The experimental fuels comprise a typical range (characterized by the Wobbe indices of 1430 to $17800 \mathrm{kcal} / \mathrm{Nm}^{3}$ ) for on-site power generation.

The LBO experiments show that the LSI with $\mathrm{S}=0.57$ supports stable flames for all seven fuels. The stability range for $0.5 \mathrm{H}_{2} / 0.5 \mathrm{CO}_{2}$ flames is limited to $\phi<0.3$ where $\mathrm{NO}_{\mathrm{x}}$ emissions are below detectible limits. $\mathrm{NO}_{\mathrm{x}}$ emissions from the hydrocarbon flames show an exponential dependence on $\phi$ and correlate with $\mathrm{T}_{\mathrm{ad}}$ and are consistent with previous measurements at $500<$ $\mathrm{T}_{0}<700 \mathrm{~K}$ and $6<\mathrm{P}_{0}<15 \mathrm{~atm}$. Despite the variations in fuel properties, the LSI is capable of supporting stable hydrocarbon flames that emit $\mathrm{NO}_{\mathrm{x}}<5 \mathrm{ppm}$ and $\mathrm{CO}$ well below acceptable limits.

Analyses of the non-reacting and reacting flowfields indicate that the overall effect of the flame is that of an aerodynamic blockage against the flow supplied through the LSI. The net result is a systematic shift of the divergence flow into the LSI, increases in the divergence rates and increases in the mean axial and radial velocities in the swirl annulus region. These effects are weaker for the flames with lower heat releases. However, the virtual origin of the flow divergence, $\mathrm{x}_{0}$, and its non-dimensional stretch rates $\mathrm{a}_{\mathrm{x}}$ show that the similarity features of the nearfield region are preserved. The turbulent flame speeds, $\mathrm{S}_{\mathrm{T}}$, of the hydrocarbon fuels are consistent with those of methane/air flames. The similarity features and linear $\mathrm{S}_{\mathrm{T}}$ correlation 
provide further support of an analytical model that explains why the lifted LSI flame does not shift with $\mathrm{U}_{0}$.

This study shows that the LSI does not need to undergo significant alterations to operate with the hydrocarbon fuels, but need further studies for adaptation to burn diluted $\mathrm{H}_{2}$ fuels.

\section{ACKNOWLEDGEMENT}

Support of this work was provided by US Dept. of Energy, Energy Efficiency and Renewable Energy with laboratory facility and instrumentation support from US Dept. of Energy, Chemical Sciences Division, both under Contract No. DE-AC02-05CH11231. The authors would like to thank Waseem Nazeer, Ken Smith, and Patrick Shepherd of Solar Turbines for making available the elevated $\mathrm{T}_{0}, \mathrm{P}_{0}$ data of Figure 2(a).

\section{REFERENCES}

[1] R. Carroni, V. Schmidt and T. Griffin, Catalysis Today, 75 (1-4) (2002) 287-295.

[2] V. R. Katta and W. M. Roquemore, Journal of Propulsion and Power, 14 (3) (1998) 273281.

[3] S. J. Greenberg, N. K. McDougald, C. K. Weakley, R. M. Kendall and L. O. Arellano, Journal of Engineering for Gas Turbines and Power-Transactions of the ASME, 127 (2) (2005) 276-285.

[4] M. R. Johnson, D. Littlejohn, W. A. Nazeer, K. O. Smith and R. K. Cheng, Proc. Comb. Inst, 30 (2005) 2867 - 2874.

[5] I. G. Shepherd, R. K. Cheng, T. Plessing, C. Kortschik and N. Peters, Proc. Comb. Institute, 29 (2002) 1833 - 1840.

[6] R. K. Cheng, D. A. Schmidt, L. Arellano and K. O. Smith, IJPGC2001, New Orleans, 2001

[7] D. T. Yegian and R. K. Cheng, Combustion Science and Technology, 139 (1-6) (1998) 207-227. 
[8] C. K. Chan, K. S. Lau, W. K. Chin and R. K. Cheng, Proc. Comb. Inst., 24 (1992) 511518.

[9] W. A. Nazeer, K. O. Smith, P. Sheppard, R. K. Cheng and D. Littlejohn, ASME Turbo Expo 2006: Power for Land, Sea and Air, Paper GT2006-90150 ASME, Barcelona, Spain, 2006,

[10] R. K. Cheng, D. T. Yegian, M. M. Miyasato, G. S. Samuelsen, R. Pellizzari, P. Loftus and C. Benson, Proc. Comb. Inst., 28 ((2000) 1305-1313.

[11] D. Littlejohn, M. J. Majeski, S. Tonse, C. Castaldini and R. K. Cheng, Proc. Comb. Inst., 29 ((2002) $1115-1121$.

[12] Q. Zhang, D. R. Noble, A. Meyers, K. Xu and T. Lieuwen, ASME Turbo Expo 2005: Power for Land Sea and Air, Paper GT2005-68907 Reno, NV, 2005.

[13] M. P. Wernet, 18th International Congress on Instrumentation for Aerospace Simulation Facilities, Toulouse, France, 1999,

[14] R. K. Cheng, D. Littlejohn, W. A. Nazeer and K. O. Smith, ASME Turbo Expo 2006: Power for Land Sea and Air, Paper GT2006-90878 ASME, Barsalona, Spain, 2006.

[15] D. Bradley, Proc. Comb. Inst., 24 (1992) 279-285.

[16] T. Plessing, C. Kortschik, M. S. Mansour, N. Peters and R. K. Cheng, Proc. Comb. Inst., 28 (2000) 359-366.

[17] R. K. Cheng, I. G. Shepherd, B. Bedat and L. Talbot, Combustion Science and Technology, 174 (1) (2002) 29-59.

[18] B. Bedat and R. K. Cheng, Combustion and Flame, 100 (3) (1995) 485-494. 


\section{TABLES}

Table I

\begin{tabular}{|l|c|l|l|}
\hline Fuel Composition & $\begin{array}{c}\mathrm{T}_{\mathrm{ad}} \text { at } \\
\phi=1 \\
\mathrm{~K}\end{array}$ & $\begin{array}{c}\mathrm{S}_{\mathrm{L}} \text { at } \\
\phi=1 \\
\mathrm{~m} / \mathrm{s}\end{array}$ & $\begin{array}{c}\text { Wobbe } \\
\text { Index } \\
\mathrm{kcal} / \mathrm{Nm}^{3}\end{array}$ \\
\hline $\mathrm{CH}_{4}$ & 2230 & 0.39 & 11542 \\
\hline $\mathrm{C}_{2} \mathrm{H}_{4}$ & 2373 & 0.74 & 14344 \\
\hline $\mathrm{C}_{3} \mathrm{H}_{8}$ & 2253 & 0.45 & 17814 \\
\hline $\mathrm{H}_{2}$ & 2318 & 2.50 & 9712 \\
\hline $0.5 \mathrm{CH}_{4} / 0.5 \mathrm{CO}_{2}$ & 2013 & 0.20 & 4182 \\
\hline $0.6 \mathrm{CH}_{4} / 0.4 \mathrm{~N}_{2}$ & 2133 & 0.31 & 6026 \\
\hline $0.6 \mathrm{CH}_{4} / 0.4 \mathrm{H}_{2}$ & 2258 & 0.57 & 10130 \\
\hline $0.5 \mathrm{H}_{2} / 0.5 \mathrm{CO}_{2}$ & 1693 & 0.56 & 1432 \\
\hline
\end{tabular}

Table II

\begin{tabular}{|c|c|c|c|c|c|c|c|}
\hline Fuel & $\phi$ & $\begin{array}{c}U_{0} \\
\mathrm{~m} / \mathrm{s}\end{array}$ & $\underset{\mathrm{mm}^{-1}}{\mathrm{a}_{\mathrm{x}}}$ & $\begin{array}{c}\mathbf{x}_{0} \\
\mathrm{~mm}\end{array}$ & $\begin{array}{c}\mathrm{S}_{\mathrm{T}} \\
\mathrm{m} / \mathrm{s}\end{array}$ & $\mathbf{u}^{\prime} / \mathbf{s}_{\mathrm{L}}$ & $\mathbf{S}_{\mathrm{T}} / \mathbf{S}_{\mathrm{L}}$ \\
\hline \multirow{3}{*}{ None } & \multirow{3}{*}{0} & 6.76 & -0.0086 & -21.41 & & & \\
\hline & & 7.47 & -0.0085 & -23.45 & & & \\
\hline & & 9.21 & -0.0082 & -24.62 & & & \\
\hline \multirow{2}{*}{$\mathrm{CH}$} & \multirow{2}{*}{0.73} & 6.23 & -0.0141 & -38.93 & 1.40 & 2.43 & 6.03 \\
\hline & & 9.27 & -0.0134 & -38.81 & 1.97 & 2.99 & 8.49 \\
\hline \multirow{2}{*}{$\mathrm{C}_{2} \mathrm{H}_{4}$} & \multirow{2}{*}{0.62} & 6.32 & -0.0140 & -33.57 & 1.62 & 2.30 & 6.23 \\
\hline & & 9.40 & -0.0130 & -45.88 & 2.17 & 3.00 & 8.35 \\
\hline \multirow{2}{*}{$\mathrm{C}_{3} \mathrm{H}_{8}$} & \multirow{2}{*}{0.69} & 6.23 & -0.0131 & -40.92 & 0.92 & 1.80 & 3.67 \\
\hline & & 9.30 & -0.0134 & -42.84 & 1.20 & 2.24 & 4.80 \\
\hline \multirow{2}{*}{$\begin{array}{l}0.5 \mathrm{CH}_{4} / \\
0.5 \mathrm{CO}_{2} \\
\end{array}$} & \multirow{2}{*}{0.83} & 6.27 & -0.0131 & -42.10 & 1.00 & 3.18 & 7.11 \\
\hline & & 9.50 & -0.0154 & -38.70 & 1.46 & 4.51 & 10.43 \\
\hline \multirow{3}{*}{$\begin{array}{l}0.6 \mathrm{CH}_{4} \\
10.4 \mathrm{~N}_{2} \\
0.6 \mathrm{CH}_{4}\end{array}$} & \multirow[b]{2}{*}{76} & 6.24 & -0.0142 & -38.94 & 1.16 & 2.45 & 6.44 \\
\hline & & 9.40 & -0.0142 & -42.75 & 1.56 & 3.69 & 8.67 \\
\hline & \multirow{2}{*}{0.65} & 6.58 & & -55.95 & 1.43 & 2.14 & 6.50 \\
\hline \multirow{2}{*}{$\begin{array}{l}0.6 \mathrm{CH}_{4} / \\
0.4 \mathrm{H}_{2}\end{array}$} & & 9.13 & -0.0120 & -45.08 & 2.24 & 2.91 & 10.18 \\
\hline & \multirow{2}{*}{0.25} & 6.48 & -0.0121 & -32.89 & 1.42 & & \\
\hline \multirow{3}{*}{$\begin{array}{l}0.5 \quad \mathrm{H}_{2} / \\
0.5 \mathrm{CO}_{2}\end{array}$} & & 9.55 & -0.0102 & -34.08 & 2.91 & & \\
\hline & \multirow{2}{*}{0.3} & 6.56 & -0.0110 & -27.27 & 2.54 & & \\
\hline & & 9.38 & -0.0094 & -33.70 & 4.00 & & \\
\hline
\end{tabular}




\section{FIGURE CAPTIONS}

Figure 1. Schematics and photographs of the low-swirl injector

Figure 2. LSI lean blow-off limits for (a) natural gas at STP and elevated $\mathrm{T}_{0}$ and $\mathrm{P}_{0}$ and for (b) fuels of Table I at STP

Figure 3. $\mathrm{NO}_{\mathrm{x}}$ and $\mathrm{CO}$ emissions from LSI for the hydrocarbon fuels of Table I

Figure 4. Comparison of $\mathrm{NO}_{\mathrm{x}}$ data from Figure 3 and from Ref [4].

Figure 5. Centerline profiles of the non-reacting flows

Figure 6. Radial profiles of the non-reacting flows at $\mathrm{x}=15 \mathrm{~mm}$

Figure 7. Centerline profiles of eight flames with $9.2<\mathrm{U}_{0}<9.5 \mathrm{~m} / \mathrm{s}$

Figure 8. Radial profiles of eight flames with $9.2<\mathrm{U}_{0}<9.5 \mathrm{~m} / \mathrm{s}$ at $\mathrm{x}=15 \mathrm{~mm}$

Figure 9. Correlation of flame speeds measured from LSI and LSB 


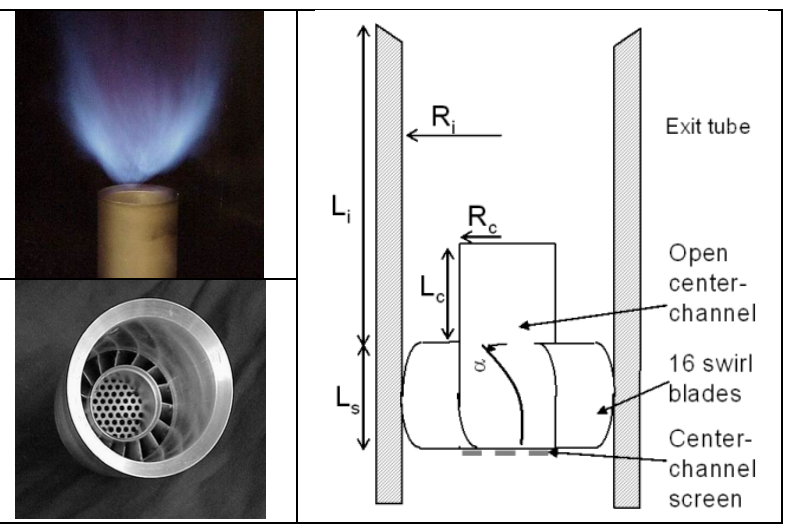

Figure 1 Schematics and photographs of the low-swirl injector
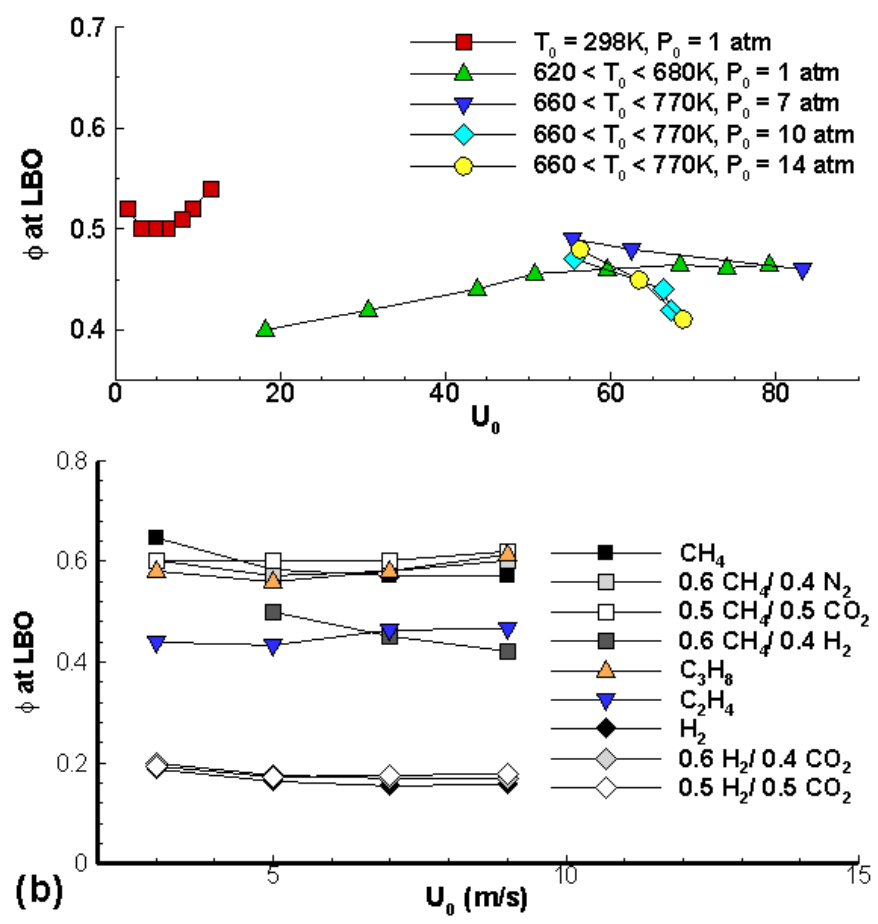

Figure 2 LSI lean blow-off limits for (a) natural gas at STP and elevated $\mathrm{T}_{0}$ and $\mathrm{P}_{0}$ and (b) for fuels of Table I at STP 

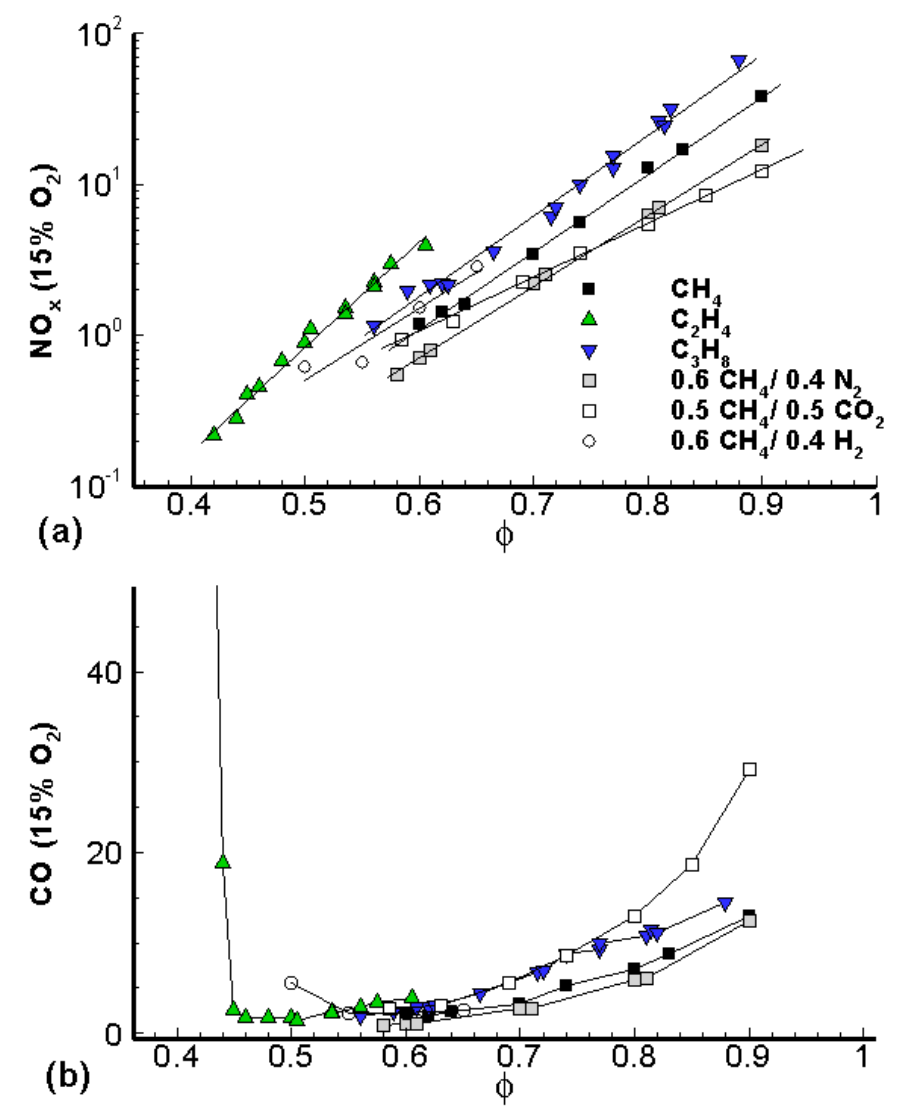

Figure $3 \mathrm{NO}_{\mathrm{x}}$ and $\mathrm{CO}$ emissions from LSI for the hydrocarbon fuels of Table I

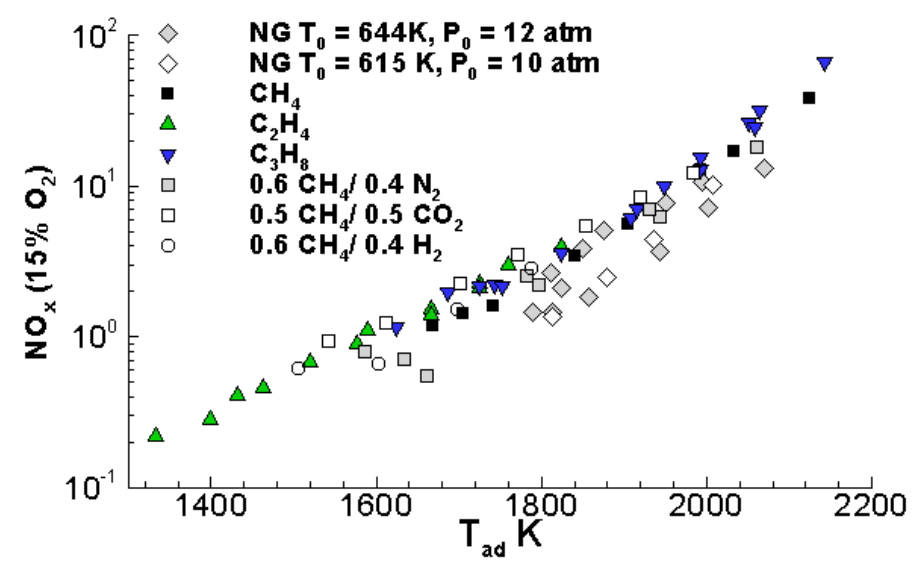

Figure 4 Comparison of $\mathrm{NO}_{\mathrm{x}}$ data from Figure 3 and from Ref [4]. 


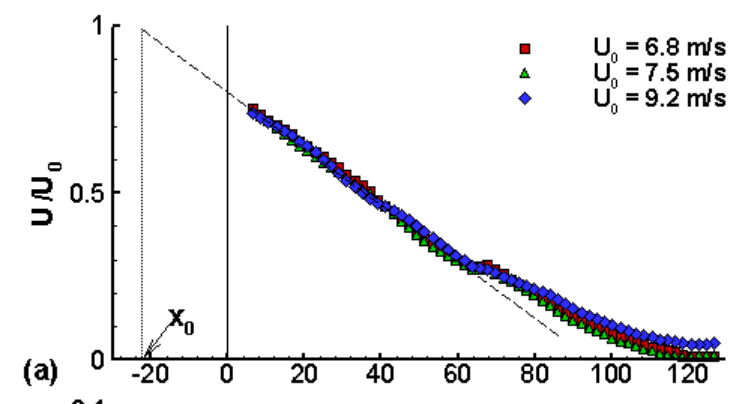

(b)

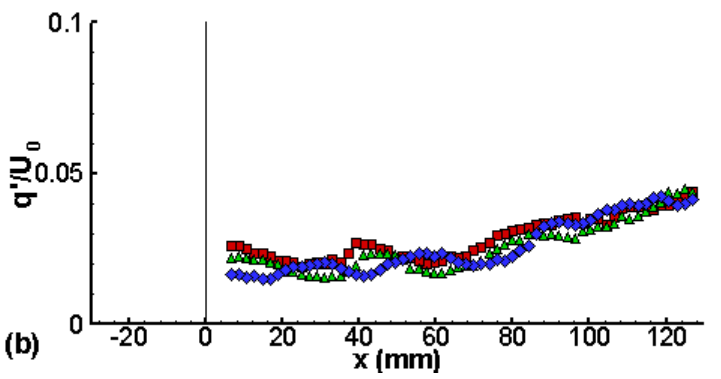

Figure 5 Centerline profiles of the non-reacting flows

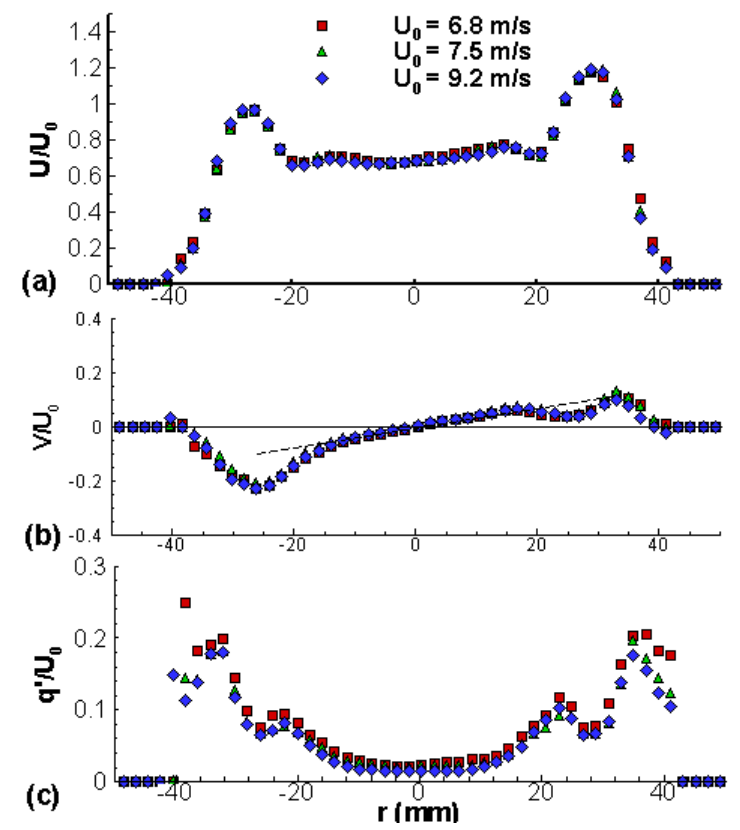

Figure 6 Radial profiles of the non-reacting flows at $x=15 \mathrm{~mm}$ 


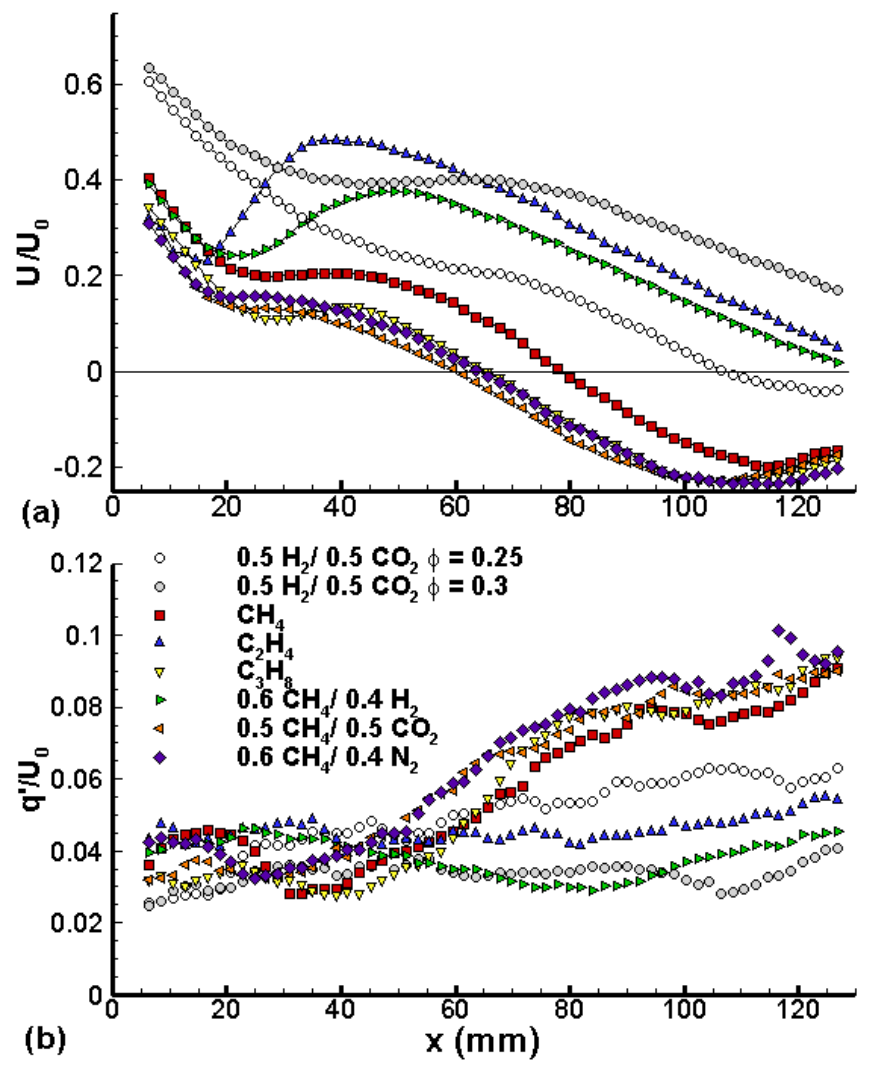

Figure 7 Centerline profiles of eight flames with $9.2<\mathrm{U}_{0}<9.5 \mathrm{~m} / \mathrm{s}$ 

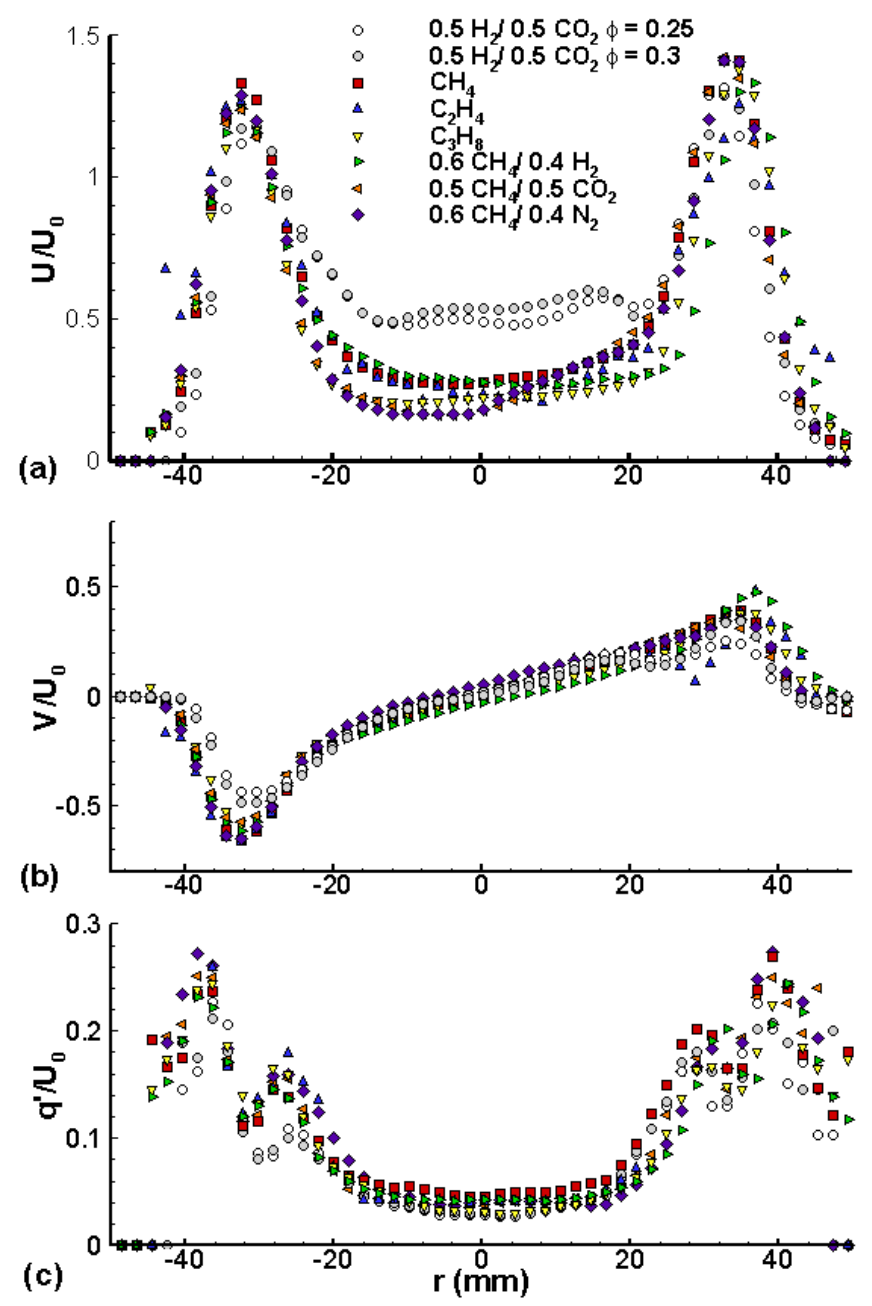

Figure 8 Radial profiles of eight flames with $9.2<\mathrm{U}_{0}<9.5 \mathrm{~m} / \mathrm{s}$ at $\mathrm{x}=15 \mathrm{~mm}$ 


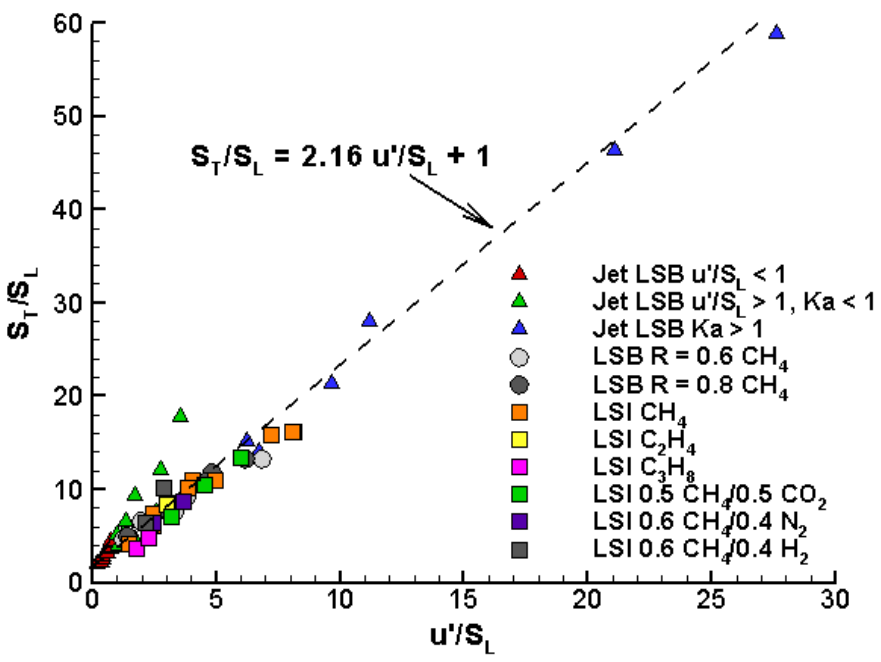

Figure 9 Correlation of flame speeds measured from LSI and LSB 